УДК 338

DOI 10.18413/2687-0932-2020-47-2-274-287

\title{
ВНЕДРЕНИЕ ИННОВАЦИЙ В РИТЕЙЛЕ И ИХ ВЛИЯНИЕ НА СТОИМОСТЬ КОМПАНИИ
}

\section{INNOVATIONS IMPLEMENTATION IN RETAIL AND ITS IMPACT ON A COMPANY VALUE}

\author{
Л.Ю. Ласкина ${ }^{1}$, Л.В. Силакова ${ }^{1}$, А.М. Варакса ${ }^{2}$ \\ L.Yu. Laskina ${ }^{1}$, L.V. Silakova ${ }^{1}$, A.M. Varaksa ${ }^{2}$ \\ 1) Университет ИТМО \\ Россия, 197101, г. Санкт-Петербург, Кронверкский проспект, д. 49 \\ 2) Новосибирский государственный университет экономики и управления \\ Россия, 630099, Новосибирск, ул. Красный проспект, 35 \\ 1) Saint Petersburg State University of Information Technologies, Mechanics and Optics \\ 49 Kronverksky Prospekt, St. Petersburg, 197101, Russia \\ 2) Novosibirsk state University of Economics and management \\ 35 Red Avenue St, Novosibirsk, 630099, Russia \\ E-mail: risk05@mail.ru, silevery@yandex.ru, anny.v@rambler.ru
}

\begin{abstract}
Аннотация
В статье рассматривается проблема оценки влияния использования современных технологий в сфере ритейла на увеличение стоимости компаний. Проводится классификация новых технологий в сфере ритейла. Анализируется и выявляется влияние применения новых технологий на такие показатели эффективности компаний, как рост товарооборота, рост прибыли и объема продаж, снижение складских, логистических и коммерческих затрат, увеличение производительности, уменьшение товарных запасов и, как следствие, повышение ликвидности и увеличение денежных потоков компании. Проводится анализ и оценка инновационного проекта по внедрению Big Data в деятельности ритейла с использованием метода прогнозирования и дисконтирования денежных потоков. Проведенное исследование позволило выявить положительную зависимость между применением новых технологий и стоимостью компании.
\end{abstract}

\begin{abstract}
The article considers the problem of assessing the impact of the use of modern technologies in the retail sector on the increase in the value of companies. The classification of new technologies in the field of retail is carried out. It analyzes and reveals the impact of the use of new technologies on such performance indicators of companies as growth in turnover, growth in profit and sales, decrease in warehouse, logistics and commercial costs, increase in productivity, decrease in inventories and, as a result, increase in liquidity and increase in cash flows of the company. The analysis and evaluation of an innovative project to introduce Big Data in retail activities using the method of forecasting and discounting cash flows is carried out. The study revealed a positive relationship between the use of new technologies and the value of the company.
\end{abstract}

Ключевые слова: инновации в ритейле, большие данные, электронная коммерция, стоимость компании, денежные потоки.

Keywords: retail innovation, big data, e-commerce, company value, cash flows.

\section{Введение}

Быстрое технологическое развитие влияет на активизацию развития и использования новых технологий в бизнесе. Согласно мнению специалистов Nielsen, существует два фактора, влияющих на изменения в сфере ритейла - это поведение потребителя и технологии. 
В настоящее время написано много аналитических статей и исследований, посвященных инновационным технологиям в ритейле [Львова, 2015]. Также имеются теоретические работы по влиянию инноваций на стоимость бизнеса, а также применительно к сфере информационных технологий, нефтегазовой отрасли. Однако в исследованиях недостаточное внимание уделяется выявлению влияния применения современных технологий на стоимость компании в сфере розничной торговли.

\section{Объекты и методы исследования}

Объектом данного исследования являются инновации в сфере ритейла.

Основными трендами в области инноваций в ритейле являются обновление инфраструктуры, использование больших данных и машинного обучения, а также введение новых форм оплаты. Наблюдается переход к более индивидуализированному подходу к покупателям, в чем помогают новые технологии [Будущее наступило: как «умные» технологии влияют на ритейл, 2018]. В целом рынок инноваций в розничной торговле можно поделить на пять больших групп:

1) технологии больших данных (Big Data), искусственного интеллекта (AI), системы видеоаналитики и компьютерного зрения (OSA, OOS) [Котик...2016];

2) инновационные форматы магазинов;

3) технологии виртуальной и дополненной реальности (VR, AR);

4) технологии автоматизации бизнес-процессов;

5) электронная коммерция.

Исследование проведено на основе анализа научных работ и публикаций в сфере инновационных технологий в сфере ритейла с использованием метода дедукции, сравнения. С применением метода дисконтирования денежных потоков проведена оценка внедрения инноваций на стоимость компании.

\section{Результаты и их обсуждение}

Проведенный анализ позволил выявить эффекты от внедрения инноваций в сфере ритейла, а также на примере инновационного проекта показать влияние внедрения одной из инновационных технологий на стоимость компании.

Характеристика представленных групп инноваций с указанием сферы их применения, а также эффект от внедрения той или иной инновации представлены в таблице 1.

Участниками рынка больших данных являются: поставщики инфраструктуры, предоставляющие программное обеспечение для хранения и обработки данных (SAP, Oracle, IBM), компании, специализирующиеся на создании алгоритмов для управления данными, системные интеграторы - компании, занимающиеся внедрением системы анализа данных (КРОК, Техносерв, Softline), потребители, разработчики готовых сервисов [Соколова, 2015]. Данные технологии требуют очень больших инвестиций, в связи с чем позволить себе их могут только крупные компании.

Таблица 1

Table 1

Группы инноваций в сфере ритейла

Innovation groups in the retail companies

\begin{tabular}{|l|l|l|}
\hline \multicolumn{1}{|c|}{ Технология } & \multicolumn{1}{|c|}{ Сфера применения } & \multicolumn{1}{|c|}{ Эффект } \\
\hline Big Data & - хранение и обработка данных; & - увеличение лояльности клиентов; \\
& предсказание поведения & - сокращение издержек на маркетинг; \\
& потребителей. & - повышение вероятности продаж; \\
& - дополнительно 7\% дохода за \\
& выбранный промежуток времени \\
& [«Инфосистемы Джет» разработала \\
& систему предсказания, 2018]. \\
\hline
\end{tabular}


Продолжение табл. 1

\begin{tabular}{|c|c|c|}
\hline Технология & Сфера применения & Эффект \\
\hline $\begin{array}{l}\text { AІ - искусственный } \\
\text { интеллект }\end{array}$ & $\begin{array}{l}\text { - совершенствование существу- } \\
\text { ющих продуктов, делающее их } \\
\text { интеллектульными; } \\
\text { - проведение глубокого и } \\
\text { эффективного анализа информации; } \\
\text { - автоматизация и оптимизация } \\
\text { процессов; } \\
\text { - предсказание } \\
\text { потребителей; } \\
\text { - создание индивидуализированных } \\
\text { предложений для клиентов согласно } \\
\text { их предпочтениям (в том числе при } \\
\text { помощи чат-ботов); } \\
\text { - сегментация клиентов; } \\
\text { - выкладка товаров в магазинах; } \\
\text { - обеспечение безопасности и } \\
\text { контроля. }\end{array}$ & $\begin{array}{l}\text { - увеличение выручки от } 1 \% \text { до } 5 \% \\
\text { [Искусственный интеллект для } \\
\text { ритейла...,2018]; } \\
\text { - рост маржинальности на 2-10 \%; } \\
\text { - увеличение цикла жизни клиента на } \\
2 \text { \%; } \\
\text { - рост среднего чека на } 50 \% \text { [X5 Retail } \\
\text { Group дал маркетингу искусственный } \\
\text { интеллект, 2017]. }\end{array}$ \\
\hline $\begin{array}{l}\text { Системы } \\
\text { видеоаналитики и } \\
\text { компьютерного зрения: } \\
\text {-OSA - доступность } \\
\text { товаров на полке; } \\
\text { - OOS (Out-Of-Stock) } \\
\text { отсутствие товаров } \\
\text { на полке. }\end{array}$ & $\begin{array}{l}\text { - контроль выкладки } \\
\text { путем воваров } \\
\text { видеоаналитики и компьютерного } \\
\text { зрения; } \\
\text { - анализ очередей у касс; } \\
\text { - защита от краж. }\end{array}$ & $\begin{array}{l}\text { - увеличение товарооборота на 2-5 \% } \\
\text { [«Инфосистемы Джет» и Intelligence } \\
\text { Retail, 2018]; } \\
\text { - уменьшение количества людей, } \\
\text { ушедших из магазина без покупок на } \\
10 \text { \%; } \\
\text { - сокращение потерь магазина на } 20 \% .\end{array}$ \\
\hline $\begin{array}{l}\text { Технологии } \\
\text { виртуальной (VR) и } \\
\text { дополненной (AR) } \\
\text { реальности. }\end{array}$ & $\begin{array}{l}\text { - проведение промоакции; } \\
\text { - в области обучения сотрудников } \\
\text { (моделирование возникающих при } \\
\text { рабочем процессе ситуации); } \\
\text { - для визуализации и презентации } \\
\text { товаров потребителям. }\end{array}$ & $\begin{array}{l}\text { - рост товарооборота сети на } 3 \% \text { и } \\
\text { более; } \\
\text { - увеличение объемов товаров, } \\
\text { участвующих в акции, от } 50 \% \text { до } \\
500 \% \text {; } \\
\text { - доля присутствия товаров- } \\
\text { участников акции в чеке составила } \\
\text { oколо } 17 \% \text { [Приложение «Смотри, } \\
\text { динозавры!», 2020]; } \\
\text { - сокращение расходов на обучение } \\
\text { работников; } \\
\text { - повышение эффективности обучения } \\
\text { [Мазлоев, 2018]; } \\
\text { - увеличение уровня сервиса } \\
\text { относительно выбранных } \\
\text { товаров на } 4 \% \text { групп } \\
\text { - рост производительности труда на } \\
8 \% \text { [Х5 Retail Group будет обучать, } \\
\text { 2019]. }\end{array}$ \\
\hline $\begin{array}{l}\text { Инновационные } \\
\text { форматы магазинов } \\
\text { А) автономные } \\
\text { магазины; } \\
\text { Б) магазин без } \\
\text { покупателей; } \\
\text { В) магазин- } \\
\text { лаборатория. }\end{array}$ & $\begin{array}{l}\text { А) для совершения покупки в } \\
\text { отсутствии продавцов и касс; } \\
\text { Б) для сбора интернет-заказов, } \\
\text { доступ в который имеется только } \\
\text { для сотрудников; } \\
\text { В) проведение тестирования } \\
\text { инноваций. }\end{array}$ & $\begin{array}{l}\text { А) - снижение затрат на оплату труда } \\
\text { персонала; } \\
\text { - ускорение и упрощение процесса } \\
\text { покупки; } \\
\text { - рост прибыли на } 50 \text { \% [Иванов, } \\
2019] \text { ]; } \\
\text { Б) повышение мощности онлайн- } \\
\text { магазина в } 3,5 \text { раза; } \\
\text { В) оптимизация затрат на электро- } \\
\text { энергию на } 15 \text { \% [Карасева, 2018]. }\end{array}$ \\
\hline
\end{tabular}


Окончание табл. 1

\begin{tabular}{|c|c|c|}
\hline Технология & Сфера применения & Эффект \\
\hline \multirow{5}{*}{$\begin{array}{l}\text { Автоматизация } \\
\text { и оптимизация } \\
\text { процессов } \\
\text { А) инновационная } \\
\text { доставка товаров; } \\
\text { Б) электронные } \\
\text { ценники; } \\
\text { B) RFID-метка; } \\
\text { Г) технология } \\
\text { самостоятельного } \\
\text { сканирования } \\
\text { товаров; } \\
\text { Д) Веасоп-маячки. }\end{array}$} & $\begin{array}{l}\text { А) Автоматизация процессов } \\
\text { покупки товаров, логистики, } \\
\text { взаимодействия с покупателями } \\
\text { (Pooling); }\end{array}$ & $\begin{array}{l}\text { А) - снижение затрат на доставку } \\
\text { грузов; } \\
\text { - уменьшение товарных запасов на } \\
8 \% \text {; } \\
\text { - уменьшение потока транспортных } \\
\text { средств на } 14 \% \text {, [Магнит» внедрил } \\
\text { новую схему поставок..., 2018]; } \\
\text { - сокращение сроков доставки товаров } \\
\text { на } 10 \% \text {. }\end{array}$ \\
\hline & $\begin{array}{l}\text { Б) проведение изменения цен в } \\
\text { реальном времени; }\end{array}$ & $\begin{array}{l}\text { Б) сокращение издержек в связи с } \\
\text { отсутствием необходимости печатать } \\
\text { цены на бумаге; } \\
\text { - снижение риска возникновения } \\
\text { ошибок при смене ценников; } \\
\text { - увеличение товарооборота на 3-5 \% } \\
\text { [Щербакова, 2018]. }\end{array}$ \\
\hline & $\begin{array}{l}\text { В) - слежение за объектом, к } \\
\text { которому он прикреплена, } \\
\text { - для маркировки товаров, } \\
\text { - оптимизация товарооборота } \\
\text { - в логистике: отслеживание } \\
\text { перемещения товара, сокращение } \\
\text { времени проведения инвентари- } \\
\text { зации, увеличение ее эффектив- } \\
\text { ности; } \\
\text { - защита магазина от краж. }\end{array}$ & $\begin{array}{l}\text { В) оптимизация расходов компании } \\
\text { - увеличение объемов продаж сети на } \\
11,5 \% \text {; } \\
\text { - снижение объема товарных потерь } \\
\text { на } 9 \% \text { [Decathlon увеличивает } \\
\text { продажи, 2016]. }\end{array}$ \\
\hline & Г) при покупке товаров & $\begin{array}{l}\text { Г) чек покупателей при применении } \\
\text { данной технологии на } 77 \% \text { выше } \\
\text { среднего чека магазина [《Перекрёсток» } \\
\text { выпустил мобильное приложение для } \\
\text { покупок, 2019]. }\end{array}$ \\
\hline & $\begin{array}{l}\text { Д) при взаимодействии с } \\
\text { потенциальными покупателями } \\
\text { при использовании Bluetooth и } \\
\text { мобильного приложения магазина; } \\
\text { - собирать данные о посетителях; } \\
\text { - доведение информации об акциях. }\end{array}$ & 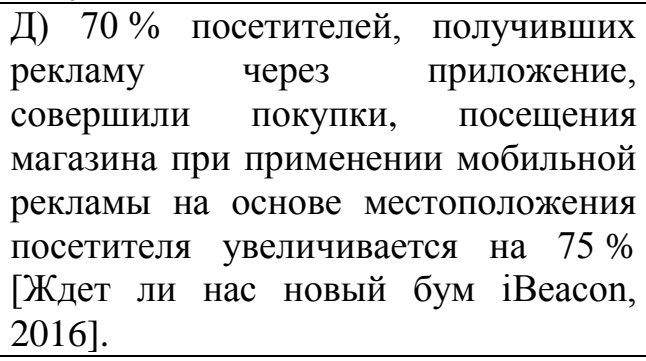 \\
\hline Интернет-торговля & $\begin{array}{l}\text { продажи осуществляются через } \\
\text { через социальные сети; } \\
\text { - позволяет клиенту самому } \\
\text { выбрать канал совершения } \\
\text { покупки }\end{array}$ & $\begin{array}{l}\text { позволяет увеличить выручку больше } \\
\text { чем на } 2 \% \text {, сократить сроки доставки, } \\
\text { увеличить пропускную способность } \\
\text { склада на } 40 \% \text {, сократить складские } \\
\text { расходы на } 20 \% \text { экономия на } \\
\text { создании сайта [Осипов, 2018]. }\end{array}$ \\
\hline
\end{tabular}

Искусственный интеллект (AI) позволяет совершенствовать существующие продукты, делая их интеллектуальными, проводить глубокий и эффективный анализ информации, автоматизировать и оптимизировать процессы. Согласно публикации KPMG к 2020 году, примерно 85 \% сделок будет происходить с применением искусственного интеллекта [Кру, 2018].

В розничной торговле существуют такие понятия как OSA (On-Shelf Availability), что означает доступность товаров на полке и OOS (Out-Of-Stock) - термин, обозначающий отсутствие товара на полке [Котик, 2016]. Компания «X5 Retail Group» внедряет системы 
видеоаналитики и компьютерного зрения для контроля выкладки товаров в магазинах. Технология работает следующим образом: система обрабатывает фотографии стеллажей в течение нескольких секунд, после чего пользователь получает отчеты, в которых отображается информация о состоянии полок с товарами, к примеру, соответствие выкладки продуктов планограмме.

В условиях быстрого развития технического прогресса под влиянием инноваций меняются не только основные процессы в работе ритейлеров, но и появляются новые форматы магазинов. Автономныле магазины - один из современных форматов в ритейле, суть которых заключается в отсутствии продавцов и касс. Примером такого формата являются магазины Amazon Go. Посетителю автоматизированного магазина Amazon Go для совершения покупки необходимо установить на свой смартфон приложение и отсканировать на входе в магазин индивидуальный штрих-код из данного приложения. Чтобы определить, какие товары покупатель взял или, если передумал, обратно поставил на полку, используются специальные датчики, сенсоры и камеры. Взятые посетителем продукты автоматически попадают в виртуальную корзину, при выходе из магазина стоимость покупки автоматически списывается с привязанной к приложению банковской карты покупателя. Подобные магазины позволяют снизить затраты на персонал и являются привлекательными для покупателя с точки зрения потребительского опыта, так как процесс покупки упрощается и ускоряется. Согласно подсчетам RBC Capital Markets, магазины Amazon Go приносят на 50 \% больше прибыли, чем традиционные магазины [Иванов, 2019].

Современные технологии имеют сильное влияние на развитие отрасли розничной торговли и в настоящее время меняют ее привычный облик. Ритейлерам приходится довольно сложно, так как конкуренция обостряется, и для того, чтобы существовать на рынке, им необходимо своевременно вводить инновации в своей деятельности. Главные изменения в розничной торговле - это ее цифровая трансформация, изменение портрета потребителя, увеличение затрат ритейлеров на инновации.

Яркой тенденцией в отрасли розничной торговли является применение технологий виртуальной (VR) и дополненной (AR) реальности. Проблемы внедрения технологий VR И AR заключаются в высокой стоимости внедрения данных технологий, отсутствии четкой гарантии эффективности технологий, недостатке квалифицированных кадров [Мокеева, 2018].

$V R$-технологии начинают активно применяться в области обучения сотрудников. Подобное обучение имеет ряд преимуществ, с помощью данной технологии можно смоделировать возникающие при рабочем процессе ситуации, и таким образом позволяет сотрудникам тренироваться и отрабатывать навыки в безопасной обстановке, которая соответствует реальной. Также внедрение обучения с помощью технологии виртуальной реальности позволяет сократить расходы на обучение работников, повышается эффективность обучения [Мазлоев, 2018].

Рассмотрим пример автоматизации целевого маркетинга в магазине «Перекресток». В ноябре 2017 компания «X5 Retail Group» автоматизировала целевой маркетинг в сети магазинов «Перекресток» при помощи внедрении технологии машинного обучения. Использование новых технологий позволяет проводить сегментацию клиентов, участвующих в программе лояльности «Клуб Перекресток», по их предпочтениям и далее создавать для них персонализированные предложения. Система учитывает такие факторы, как частота покупок, предпочитаемые товары, демографические факторы, оптимальный для покупателя уровень цен, а также выбирает наиболее эффективный способ связи с клиентом. Согласно итогам использования автоматизации целевого маркетинга, в 2018 году компания получила более 5 млрд рублей дополнительного оборота. Сумма покупок клиентов, получавших персонализированные предложения, составила 42 млрд рублей, что соответствует 16,3\% от выручки сети магазинов. Также применение новой технологии способствует увеличению среднего роста чека, по результатам некоторых маркетинговых кампаний, образованным с помощью системы, рост среднего чека достигал 50 \% [Андреева, 2017]. 
К сфере цифровизации торговли относится активное развитие интернет-торговли, даже компании сферы продуктового ритейла начинают открывать свои интернет-магазины. Согласно данным АКИТ, объем рынка интернет-торговли в 2017 году составил 1,04 трлн рублей, это на $13 \%$ больше, чем в прошлом году. На рис. 1 можно наблюдать рост рынка интернет-торговли в России и прогноз АКИТ на 2018 год. Невысокий рост в 2015 году объясняется снижением покупательной способности в связи с экономической ситуацией в стране в этот период. Торговля с помощью интернета в России составляет всего 3 \%, когда Великобритании эта цифра составляет 18 \% [Оборот российского рынка интернет-ритейла, 2018].

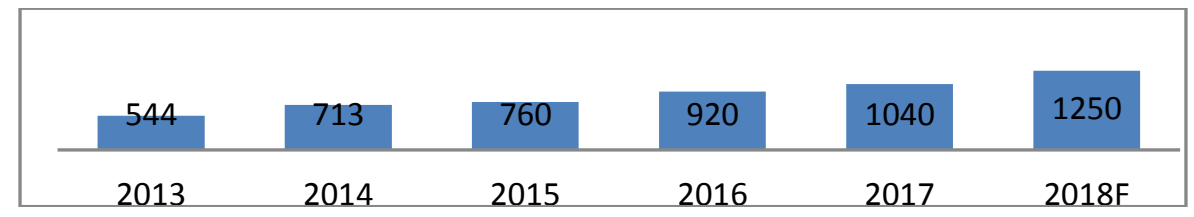

Рис. 1. Объем рынка интернет-торговли в России

Fig. 1. The volume of the online trading market in Russia

В России покупки преимущественно совершаются с помощью персональных компьютеров, однако покупки через мобильные телефоны растут, в 2017 году доля покупок через компьютеры составила 52,5 \%, а через мобильные телефоны - 47,5 \% [Мазлоев, 2018]. Также наблюдается такая тенденция как омниканальность - это интеграция онлайн и офлайн продаж, предоставление одинакового набора товаров и акций в обоих каналах.

Растут расходы компаний отрасли ритейла на инновации, инвестиции в новые технологии. На поиски инноваций и создание оптимальных бизнес-моделей уделяется много внимания. Так, компания «X5 Retail Group» активно инвестирует в новые технологии, в первом квартале 2018 года инвестиции составили $11 \%$ от капитальных затрат [Годовой отчёт X5 Retail Group, 2017]. В 2017 году компания стала сотрудничать с Фондом развития интернетинициатив, ФРИИ создаст ритейл-трэк в акселераторе. Наиболее успешные стартапы «Х5 Retail Group» будет тестировать в своих бизнес-процессах, данное сотрудничество поможет компании найти новые инновационные решения [ФРИИ и X5 Retail Group, 2017]. Также компания сотрудничает с фондом «Сколково» в области инноваций в ритейле. Компании помимо инвестирования в инновации для привлечения клиентов и увеличения продаж, активно вкладывают в автоматизацию бизнес-процессов. Компания «М.Видео» внедрила систему управления лояльностью на базе SAP CRM, программа позволила сократить время на обработку промоакций в пять раз [«М.Видео» в пять раз сократила время, 2016]. Ритейлер «Х5 Retail Group» также использует современные технологии по автоматизации, так, в отчете компания указала, что обеспечивает постоянный рост системы SAP ERP до 2020 года.

Развиваются стартап-акселераторы в сфере розничной торговли. В сентябре 2018 года прошел стартап-акселератор, направленный на разработку сервисов в области машинного обучения и больших данных Фонда развития интернет-инициатив и компании «Леруа Мерлен». Инвестиции ФРИИ в прошедшие отбор стартапы составят от 2,5 до 25 млн руб. «Яндекс. Маркет» в партнерстве c GoTech также организовали конкурс стартапов в сфере ритейла.

Использование каждой технологии приносит свои эффекты, среди которых повышение объема продаж, повышение уровня лояльности потребителей, увеличение товарооборота, снижение затрат, увеличение производительности.

Инновационная деятельность является необходимой составляющей для компании, желающей увеличить свою стоимость, так как в рамках сложившейся действительности инновации являются важнейшим конкурентным преимуществом.

В силу того, что главной целью компании является увеличение ее стоимости, проанализируем, как повлияет внедрение тех или иных инноваций на стоимость компании. В основе одного из самых распространенных подходов оценки стоимости компании доходного подхода - лежит модель дисконтированного денежного потока (DCF). 
Проекты на основе Big Data и ИИ влияют на лояльность потребителей, что с точки зрения факторов стоимости влияет на рост нематериальных активов, а именно на рыночный капитал, так как идет улучшение репутации компании. Наблюдается влияние на снижение коммерческих издержек за счет автоматизации процессов маркетинга, также технология позволяет увеличить средний чек покупателей и побуждать их делать повторные покупки, что влияет на объем продаж. Повышается эффективность управления запасами магазинов, что ведет к росту продаж и снижению потерь и издержек.

Использование технологий виртуальной и дополненной реальности в розничной торговле позволяет увеличить объем продаж, товарооборот, так как данные технологии позволяют визуализировать товар или добавить развлекательную составляющую, что привлекает потребителей. Снижаются операционные расходы на проектирование помещений. Растет производительность труда, влияющая на объем продаж и сокращение себестоимости. Уменьшаются издержки на обучение персонала и увеличивается эффективность обучения, в связи с безопасностью и удобством применения технологии.

Инновационные форматы магазинов, относительно факторов стоимости, увеличивают объем продаж, повышают лояльность потребителя, создают привлекательность с точки зрения потребительского опыта, увеличивая рыночную привлекательность, отражающуюся на росте нематериальных активов, позволяют выбрать наиболее результативные решения. Формат dark store с автоматизацией работы склада и процесса сбора интернет-заказа, увеличивает производительность работы магазина, что сказывается на издержках и увеличении объема продаж. В полностью автоматизированных магазинах, в которых нет продавцов, снижаются издержки на персонал, повышается эффективность управления запасами, благодаря умным полкам.

Инновации, направленные на автоматизацию логистических процессов, позволяют уменьшить объем запасов и товарных потерь, сокращают затраты на логистику, уменьшая затраты на такой фактор как коммерческие затраты, сокращают время доставки продукции, что влияет на объем продаж. Применение автоматизированного процесса ценообразования влияет на рост товарооборота, что влияет на объем продаж и запасы, в связи с отсутствием изготовления бумажных ценников снижаются общехозяйственные и административные затраты и затраты на персонал. Использование RFID технологии влияет на фактор объема продаж, а снижение товарных потерь влияет на запасы. Автоматизация сканирования и оплаты товаров улучшает потребительский опыт, что приводит к росту продаж и имиджа компании. Использование маячков для автоматизации маркетинга позволяет увеличить объем продаж при помощи привлечения новых клиентов и роста частоты посещаемости магазина.

Относительно влияния инновационных процессов на факторы стоимости в интернетторговле, то использование омникальности сокращает сроки доставки товаров, делает покупку товаров более комфортным, что повышает объем продаж, сокращает складские расходы, уменьшая коммерческие затраты, увеличивает пропускную способность склада, что уменьшает товарные запасы. Применение социальных сетей для продаж позволяет увеличить объем продаж в связи с охватом большей аудитории и снизить общехозяйственные и административные затраты в связи с отсутствием необходимости создания сайта, однако данный канал больше применим для небольших магазинов. Внедрение чат-ботов в деятельность компании оптимизирует взаимодействие с клиентами и снижает издержки на персонал. Система Click\&Collect увеличивает объем продаж в связи с удобством использования для потребителя, а также снижает затраты на персонал, расходы на логистику, влияя на фактор коммерческих затрат.

Больше всего эффектов, влияющих на стоимость, выражено в операционном денежном потоке. Ниже, на рис. 2, представлена схема, которая отражает, какими конкретно группами инноваций и какие изменения вызывают рост стоимости компании.

Таким образом, внедрение инновационного процесса может оказать комплексный эффект на факторы стоимости компании. 


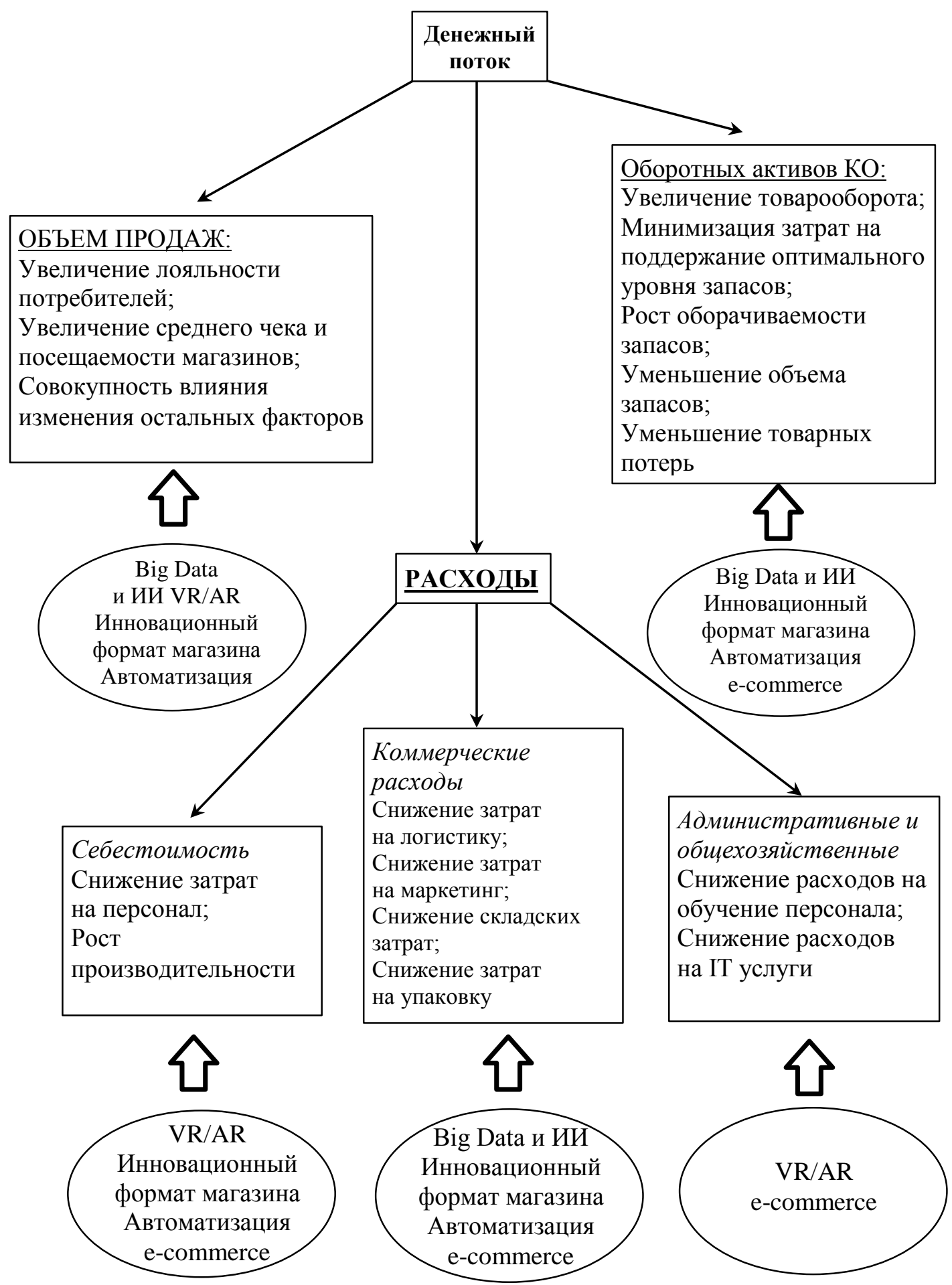

Рис. 2. Схема влияния различных групп инноваций на операционный денежный поток

Fig. 2. Diagram of the impact of various innovation groups on operating cash flow

Рассмотрим разработку инновационного проекта по внедрению технологии больших данных в компании «X5 Retail Group». Проект заключается в применении технологий больших данных и машинного обучения для создания персонализированного подхода к клиентам, а именно, это разработка решений, позволяющих создавать автоматизированные персональные предложения для покупателей, обладающих картами программы лояльности сети «Пятёрочка». Компания начала выпуск карт постоянного покупателя в 2017 году. На 2018 год владельцами данных карт стали более 28000000 человек [Гортинская, 2018]. Такое количество потенциальных данных о клиентах делает целесообразным внедрение технологии больших данных. В настоящий момент увеличение выручки и рост компании за счёт 
расширения торговых площадей и инфляции становится все менее эффективным [Ищенко, 2018]. Также наблюдается падение темпов роста сопоставимых продаж, в третьем квартале 2017 года рост LFL составил 4,6 \%, когда в 3 квартале 2018 года всего 0,5 \% [Карасева, 2018]. В рамках жесткой конкуренции в отрасли розничной торговли нужны новые способы роста эффективности деятельности компании, поэтому компания пересматривает свою стратегию в пользу развития инноваций.

Для осуществления проекта требуется внедрение комплекса технологий для клиентской аналитики и осуществления персонализированного маркетинга. Необходимый комплекс инструментов позволяет получать информацию о клиентах, обрабатывать обезличенные данные, делить клиентов на сегменты, выявлять наиболее выгодные акции магазина, реализовывать индивидуализированные предложения для покупателей, также включены предсказательные аналитические модели. Происходит переход от массовых предложений к точечным коммуникациям с клиентами [Гортинская, 2018].

Результатом проекта должен стать рост выручки компании, увеличение конкурентоспособности, повышение эффективности акционных предложений, увеличение ценности для потребителей. Также существует возможность дальнейшего развития технологии больших данных и её использования в новых проектах.

Таким образом, всего сумма инвестиций на проект составляет 753,157 млн рублей.

После расчета необходимой суммы инвестиций проведем расчет денежных потоков компании с учетом эффекта от внедрения инновационного проекта. В связи со спецификой инновационных проектов, связанных с внедрением инноваций в сфере IT, составим прогноз денежных потоков относительно роста выручки, который произойдет вследствие внедрения проекта.

Учитывая влияние вышеперечисленных факторов на рост различных показателей эффективности, в среднем получается от 2,5-3,5 \% [Искусственный интеллект для ритейла, 2018], [«Инфосистемы Джет» разработала систему предсказания, 2018], [«Инфосистемы Джет» и Intelligence Retail, 2018]. Это дает основание предположить, что осуществление проекта приведет к увеличению выручки в первый год на 1,5\%, второй год на 3 \%, третий год на 3,5\%, а на четвертом и пятом году после внедрения эффективность будет постепенно падать в связи с устареванием проекта.

Так как компания является очень крупной и занимает лидирующее положение в своей отрасли, проект будет финансироваться за счет собственных средств, поэтому компании как собственнику средств целесообразно при оценке инвестиционного проекта использовать денежные потоки на собственный капитал, потому что результат проекта важен для акционеров компании.

Формула расчета денежного потока на собственный капитал:

$$
\mathrm{FCFE}=\mathrm{NI}+\mathrm{DA}+\mathrm{Net} \text { Borrowing }-\mathrm{CapEx}-\Delta \mathrm{NWC},
$$

где NI - чистая прибыль предприятия;

DA - амортизационные отчисления;

Net Borrowing - чистые заимствования предприятия;

CapEx - капитальные затраты;

$\triangle \mathrm{NWC}$ - прирост чистого оборотного капитала.

Таким образом, относительно показателей эффективности, проект является высокоэффективным. В данном случае это связано с тем, что в связи с отсутствием финансовой отчетности сети «Пятёрочка», увеличение выручки от проекта показано не относительно одной сети компании, а отражается на всей компании в целом. Однако данные результаты также отражают суть инновации технологии больших данных и автоматизации производства, так как при грамотном применении этих инструментов они являются очень высоко маржинальными. 
Таблица 2

Table 2

Прогноз чистого денежного потока на собственный капитал (млн руб.)

Net cash flow forecast for equity (mln rubles)

\begin{tabular}{|l|c|c|c|c|c|c|}
\hline \multicolumn{1}{|c|}{ Год } & $\mathbf{2 0 1 7}$ & $\mathbf{2 0 1 8}$ & $\mathbf{2 0 1 9}$ & $\mathbf{2 0 2 0}$ & $\mathbf{2 0 2 1}$ & $\mathbf{2 0 2 2}$ \\
\hline Валовая выручка & 1295008 & 1314433 & 1353866 & 1401251 & 1436283 & 1465008 \\
\hline Себестоимость продаж & 986070 & 998969 & 1028938 & 1064951 & 1091575 & 1113406 \\
\hline Валовая прибыль (убыток) & 308938 & 315464 & 324928 & 336300 & 344708 & 351602 \\
\hline $\begin{array}{l}\text { Коммерческие и управленческие } \\
\text { расходы }\end{array}$ & 259376 & 276031 & 284312 & 294263 & 301619 & 307652 \\
\hline Прибыль (убыток) от продажи & 49562 & 39433 & 40616 & 42038 & 43088 & 43950 \\
\hline Прочие доходы & 8392 & 14459 & 14893 & 15414 & 15799 & 16115 \\
\hline Прочие расходы & 61 & 1052 & 1083 & 1121 & 1149 & 1172 \\
\hline $\begin{array}{l}\text { Прибыль до уплаты процентов } \\
\text { и налога на прибыль (ЕВІТ) }\end{array}$ & 57954 & 52840 & 54425 & 56330 & 57739 & 58893 \\
\hline Проценты к уплате & 16138 & 20079 & 20682 & 21406 & 21941 & 22379 \\
\hline $\begin{array}{l}\text { Прибыль до уплаты налога } \\
\text { на прибыль (ЕВТ) }\end{array}$ & 41816 & 32761 & 33744 & 34925 & 35798 & 36514 \\
\hline Налог на прибыль & 8364 & 6552 & 6749 & 6985 & 7160 & 7303 \\
\hline Чистая прибыль & 33452 & 26209 & 26995 & 27940 & 28638 & 29211 \\
\hline + Начисленная амортизация & 38435 & 39742 & 41451 & 43026 & 44747 & 46537 \\
\hline $\begin{array}{l}\text { + Прирост задолженности } \\
\text { долгосрочные и краткосрочные } \\
\text { кредиты и займы) }\end{array}$ & 8263 & 39564 & 41266 & 42835 & 44549 & 46331 \\
\hline $\begin{array}{l}\text { - Прирост собственного } \\
\text { оборотного капитала }\end{array}$ & -7608 & -8736 & -8440 & -7739 & -6494 & -4529 \\
\hline $\begin{array}{l}\text { - Капитальные вложения } \\
\text { Чистый денежный поток }\end{array}$ & 198600 & 101952 & 106336 & 110377 & 114792 & 119384 \\
\hline
\end{tabular}

Таблица 3

Table 3

Расчет дисконтированных показателей инновационного проекта

Calculation of discount indicators of an innovative project

\begin{tabular}{|l|c|c|c|c|c|}
\hline \multicolumn{1}{|c|}{ Год } & $\mathbf{2 0 1 8}$ & $\mathbf{2 0 1 9}$ & $\mathbf{2 0 2 0}$ & $\mathbf{2 0 2 1}$ & $\mathbf{2 0 2 2}$ \\
\hline Чистый денежный поток & 12298000 & 11815000 & 11162000 & 9635000 & 7223000 \\
\hline Инвестиции & 609435 & 48493 & 31743 & 31743 & 31743 \\
\hline Коэффициент дисконтирования & 0,86 & 0,73 & 0,63 & 0,54 & 0,46 \\
\hline $\begin{array}{l}\text { Дисконтированный денежный } \\
\text { поток }\end{array}$ & 10576280 & 8624950 & 7032060 & 5202900 & 3322580 \\
\hline
\end{tabular}


Окончание табл. 3

\begin{tabular}{|l|c|c|c|c|c|}
\hline \multicolumn{1}{|c|}{ Год } & $\mathbf{2 0 1 8}$ & $\mathbf{2 0 1 9}$ & $\mathbf{2 0 2 0}$ & $\mathbf{2 0 2 1}$ & $\mathbf{2 0 2 2}$ \\
\hline $\begin{array}{l}\text { Дисконтированный денежный } \\
\text { поток нарастающим итогом }\end{array}$ & 10576280 & 19201230 & 26233290 & 31436190 & 34758770 \\
\hline Дисконтированные инвестиции & 524114 & 35400 & 19998 & 17141 & 14602 \\
\hline $\begin{array}{l}\text { Дисконтированные инвестиции } \\
\text { нарастающим итогом }\end{array}$ & 524114 & 559514 & 579512 & 596653 & 611255 \\
\hline
\end{tabular}

\section{Заключение}

Выявленный эффект влияния инновационных технологий в ритейле на показатели деятельности розничной торговли позволил использовать их в прогнозировании и оценке денежных потоков при внедрении одной из рассматриваемых технологий (больших данных) в деятельности группы компаний.

Учитывая высокую конкуренцию в отрасли и снижение эффективности от традиционных методов увеличения роста компании, применение новых технологий является самым оптимальным решением для компании. Предложенный проект по внедрению технологий больших данных в работу компании позволит не только увеличить лояльность покупателей, но и сократить ряд издержек, к примеру, на коммуникации, и увеличить рентабельность продаж, а также найти широкое применение и развитие данной технологии в дальнейшем.

\section{Список литературы}

1. Андреева M. X5 Retail Group дал маркетингу искусственный интеллект. ComNews. 2017. URL: https://www.comnews.ru/content/1 10307/2017-11-02/x5-retail-group-dal-marketingu-iskusstvennyyintellekt (дата обращения: 20.02.2020).

2. ВЭБ вкладывается в электронные ценники. URL: https://www.comnews.ru/content/ 111326/2018-01-18/veb-vkladyvaetsya-v-elektronnye-cenniki (дата обращения: 27.02.2020)

3. Годовой отчёт X5Retail Group. X5 Retail Group. 2017. URL: https://www.x5.ru/ ru/PublishingImages/Pages/Investors/ResultsCentre/X5_Annual_Report_2017_RUS.pdf (дата обращения: 04.03.2020).

4. Гортинская У. GlowByte внедрила комплекс инструментов клиентской аналитики в рамках программы лояльности «Выручай-карта» для сети «Пятерочка». Cnews.ru. 2018. URL: http://www.cnews.ru/news/line/2018-10-03_glowbyte_vnedrila_kompleks_instrumentov_klientskoj (дата обращения: 28.03.20).

5. Ждет ли нас новый бум iBeacon-сервисов в российском ритейле: кто возглавит гонку? Журнал Retail \& Loyalty. 2016. URL: https://www.retail-loyalty.org/expert-forum/zhdet-li-nas-novyy-bumibeacon-servisov-v-rossiyskom-riteyle-kto-vozglavit-gonku/?id=198477 (дата обращения: 27.02.2020).

6. Иванов С. Автоматизированные магазины Amazon Go оказались в 1,5 раза прибыльнее обычных. Хайтек. 2019. URL: https://hightech.fm/2019/01/07/amazon-go-effect (дата обращения: 25.02.2020).

7. «Инфосистемы Джет» и Intelligence Retail внедряют компьютерное зрение в ретейле. URL: https://www.comnews.ru/content/114005/2018-07-18/infosistemy-dzhet-i-intelligence-retail-vnedryayut-kom pyuternoe-zrenie-v-reteyle (дата обращения: 20.02.2020).

8. «Инфосистемы Джет» разработала систему предсказания поведения покупателей для «Рив Гош». URL: http://www.cnews.ru/news/line/2018-05-16_infosistemy_dzhet_razrabotala_sistemu_predskazaniya (дата обращения: 12.02.2020).

9. Искусственный интеллект для ритейла: какие результаты получит бизнес. URL: https://vc.ru/trade/48616-iskusstvennyy-intellekt-dlya-riteyla-kakie-rezultaty-poluchit-biznes дата обращения: 12.02.2020). 
10. Ищенко H. X5 Retail Group c помощью big data хочет лучше изучить клиентов. Vedomosti.ru. 2018. URL: https://www.vedomosti.ru/business/articles/2018/03/01/752359-x5-big-data (дата обращения: 28.03.2020).

11. Карасева О. Кибермаркет: Как устроен магазин-лаборатория «Пятерочка», X5 открыла магазин-лабораторию для разработки инноваций. The Village. 2018. URL: https://www.thevillage.ru/village/business/management/330341-innovatsionnaya-pyaterochka (дата обращения: 25.02.2020).

12. Котик C. On Shelf Availability в российской рознице: не потерять продажи. Retail\&Loyalty. №1 (55). 2016. URL: https://www.retail-loyalty.org/journal_retail_loyalty/read_online/art189509/ (дата обращения: 20.02.2020).

13. Кру В., Кунан Д., Девани Д. Глобальные тенденции развития сектора розничной торговли в 2018 году. Публикация KPMG International Cooperative. 2018. 33 c. URL: https://assets.kpmg/content/ $\mathrm{dam} / \mathrm{kpmg} / \mathrm{ru} / \mathrm{pdf} / 2018 / 06 / \mathrm{ru}-\mathrm{ru}$-global-retail-trends-2018.pdf (дата обращения: 12.02.2020).

14. Львова И.А., Семёнова И.А. 2015. Инновации в торговом процессе. Вестник Удмурдского университета. Серия Экономика и право. Т.25. Вып. 6. С.27-32.

15. «М.Видео» в пять раз сократила время обработки промоакций при переходе на SAP. Comnews.ru. 2016. URL: https://www.comnews.ru/content/104814/2016-11-22/mvideo-v-pyat-raz-sokratilavremya-obrabotki-promoakciy-pri-perehode-na-sap (дата обращения: 04.03.2020).

16. «Магнит» внедрил новую схему поставок Pooling. Magnit-info.ru. 2018. URL: http://magnitinfo.ru/press/news/detail.php?ID=26373300 (дата обращения: 25.02.2020).

17. Мазлоев А. Виртуальные классы, обучающие игры и симуляторы для тренировок: как VR и AR изменят подготовку персонала. Rusbase. 2018. URL: https://rb.ru/opinion/vr-ar-personal/ (дата обращения: 25.02.2020).

18. Мокеева И.А., Тесленко И.Б. Применение технологий виртуальной и дополненной реальности в бизнесе. Новая наука: теоретический и практический взгляд. 2018. С. 62-66.

19. Оборот российского рынка интернет-ритейла превысил 1 трлн рублей. Комерсантъ. 2018. URL: https://www.kommersant.ru/doc/3593460 (дата обращения: 04.03.2020).

20. Осипов А. 2018. Как инновационные решения спасают магазины одежды и обуви. Vc.ru. URL: https://vc.ru/trade/50935-kak-innovacionnye-resheniya-spasayut-magaziny-odezhdy-i-obuvi (дата обращения: 27.02.2020).

21. «Перекрёсток» выпустил мобильное приложение для покупок по сценарию Self Scan. Newretail.ru. 2019. URL: https://new-retail.ru/novosti/retail/perekryestok_vypustil_mobilnoe_prilozhenie_ dlya_pokupok2388/ (дата обра- щения: 27.02.2020).

22. Приложение «Смотри, динозавры!» скачали $500 \quad 000$ человек. 2020. Журнал Retail\&Loyalty. №2 (89). URL: https://www.retail-loyalty.org/news/prilozhenie-smotri-dinozavryskachali-500-000-chelovek/ (дата обращения: 20.02.2020).

23. Соколова А. 2015. Как устроен рынок big data в России. Rusbase. URL: https://rb.ru/howto/big-data-in-russia/ (дата обращения: 27.02.2020).

24. ФРИИ и X5 Retail Group запускают программу стратегического партнерства. 2017. Iidf.ru. URL: http://www.iidf.ru/media/articles/fond/frii-i-x5-retail-group-zapuskayut-programmu-strategicheskogopartnerstva/ (дата обращения: 4.03.2020).

25. Щербакова А. 2018. Будущее наступило: как «умные» технологии влияют на ритейл. ComNews. URL: https://www.retail.ru/articles/148995 (дата обращения: 25.02.2020).

26. Decathlon увеличивает продажи и снижает потери благодаря RFID. 2016. RFIDJournal.com.

URL: https://www.idexpert.ru/reviews/decathlon-uvelichivaet-prodazhi-i-snizhaet-poteri-blagodarya-rfid/? sphrase_id=10284797 (дата обращения: 27.02.2020).

27. X5 Retail Group будет обучать персонал в VR-очках. 2019. Retail.ru. URL: https://www.retail.ru/news/x5-retail-group-budet-obuchat-personal-v-vr-ochkakh/ (дата обращения: 20.02.2020).

\section{References}

1. Andreeva M. 2017. X5 Retail Group gave marketing artificial intelligence. ComNews. URL: https://www.comnews.ru/content/110307/2017-11-02/x5-retail-group-dal-marketingu-iskusstvennyy-intellekt (accessed date: 02.20.2020).

2. VEB is invested in electronic price tags. URL: https://www.comnews.ru/content/111326/2018-0118/veb-vkladyvaetsya-v-elektronnye-cenniki (accessed: 02.27.2020). 
3. Annual report of X5Retail Group.X5 Retail Group. 2017. URL: https://www.x5.ru/en/PublishingImages/Pages/Investors/ResultsCentre/X5_Annual_Report_2017_RUS.pdf (accessed 04.03.2020).

4. Gortinskaya U. GlowByte introduced a set of client analytics tools as part of the "Help-card" loyalty program for the Pyaterochka network. Cnews.ru. 2018. URL: http://www.cnews.ru/news/line/ 2018-1003_glowbyte_vnedrila_kompleks_instrumentov_klientskoj (accessed date: 03/28/20).

5. Is there a new boom of iBeacon services in Russian retail waiting for us: who will lead the race? Journal of Retail \& Loyalty. 2016. URL: https://www.retail-loyalty.org/expert-forum/zhdet-li-nas-novyybum-ibeacon-servisov-v-rossiyskom-riteyle-kto-vozglavit-gonku/?id = 198477 (circulation date: 02.27.2020).

6. Ivanov S. Amazon Go automated stores were 1.5 times more profitable than usual. Haytek. 2019. URL: https://hightech.fm/2019/01/07/amazon-go-effect (accessed: 02.25.2020).

7. Jet Infosystems and Intelligence Retail deploy computer vision in retail. URL: https://www.comnews.ru/content/114005/2018-07-18/infosistemy-dzhet-i-intelligence-retail-vnedryayutkompyuternoe-zrenie-v-reteyle (accessed: 02.20.2020).

8. Jet Infosystems has developed a system for predicting customer behavior for Rive Gauche. URL: http://www.cnews.ru/news/line/2018-05-16_infosistemy_dzhet_razrabotala_sistemu_predskazaniya (accessed: 12.02.2020).

9. Artificial intelligence for retail: what results the business will receive. URL: https://vc.ru/trade/48616iskusstvennyy-intellekt-dlya-riteyla-kakie-rezultaty-poluchit-biznes (accessed: 02/12/2020) .

10. Ishenko N. 2018. X5 Retail Group with the help of big data wants to study customers better. Vedomosti.ru. URL: https://www.vedomosti.ru/business/articles/2018/03/01/752359-x5-big-data (accessed date: 03/28/2020).

11. Karaseva O. 2018. Cybermarket: How the Pyaterochka store-laboratory works, X5 opened a storelaboratory for innovation development. The Village. URL: https://www.the-village.ru/village/business/ management/330341-innovatsionnaya-pyaterochka (accessed: 02.25.2020).

12. Kotik S. 2016. On Shelf Availability in Russian retail: do not lose sales. Retail \& Loyalty. No. 1 (55). URL: https://www.retail-loyalty.org/journal_retail_loyalty/read_online/art189509/(accessed: 02.20.2020).

13. Crew V., Kunan D., Devani D. 2018. Global trends in the development of the retail sector in 2018. Publication of KPMG International Cooperative. 33 p. URL: https://assets.kpmg/content/dam/ kpmg/en/pdf/2018/06/en-ru-global-retail-trends-2018.pdf (accessed: 02/12/2020).

14. Lvov I.A., Semenova I.A. 2015. Trading Innovation. Bulletin of the Udmurd University. Series Economics and Law. T. 25. Issue 6. S. 27-32.

15. "M. Video" five times reduced the processing time for promotions when switching to SAP. 2016. Comnews.ru. URL: https://www.comnews.ru/content/104814/2016-11-22/mvideo-v-pyat-raz-sokratilavremya-obrabotki-promoakciy-pri-perehode-na-sap (Date of appeal: 03/04/2020).

16. "Magnet" has introduced a new supply chain Pooling. 2018. Magnit-info.ru. URL: http://magnitinfo.ru/press/news/detail.php?ID=26373300 (accessed: 02.25.2020).

17. Mazloev A. 2018. Virtual classes, educational games and training simulators: how VR and AR will change staff training. Rusbase. URL: https://rb.ru/opinion/vr-ar-personal/ (accessed: 02.25.2020).

18. Mokeeva I.A., Teslenko I.B. 2018. Application of virtual and augmented reality technologies in business. New science: theoretical and practical view. S. 62-66.

19. The turnover of the Russian Internet retail market exceeded 1 trillion rubles. Komersant. 2018. URL: https://www.kommersant.ru/doc/3593460 (accessed 04.03.2020).

20. Osipov A. How innovative solutions save clothing and shoe stores. 2018. Vc.ru. URL: https://vc.ru/trade/50935-kak-innovacionnye-resheniya-spasayut-magaziny-odezhdy-i-obuvi (accessed: 02.27.2020).

21. "Crossroads" released a mobile application for shopping according to the script Self Scan. Newretail.ru.2019. URL: https://new-retail.ru/novosti/retail/perekryestok_vypustil_mobilnoe_prilozhenie_dlya_ pokupok2388/ (appeal date: 02.27.2020).

22. Appendix “Look, dinosaurs!” 500,000 people downloaded. Retail \& Loyalty Magazine. No. 2 (89). 2020. URL: https://www.retail-loyalty.org/news/prilozhenie-smotri-dinozavry-skachali-500-000-chelovek/ (accessed: 02.20.2020).

23. Sokolova A. 2015. How is the big data market in Russia. Rusbase. URL: https://rb.ru/howto/bigdata-in-russia/ (accessed: 02.27.2020).

24. IIDF and X5 Retail Group launch a strategic partnership program. 2017. Iidf.ru. URL: http://www.iidf.ru/media/articles/fond/frii-i-x5-retail-group-zapuskayut-programmu-strategicheskogopartnerstva/ (accessed: 4.03.2020). 
25. Scherbakova A. The future has come: how "smart" technologies affect retail. 2018. ComNews. URL: https://www.retail.ru/articles/148995 (accessed: 02.25.2020).

26. Decathlon increases sales and reduces losses thanks to RFID. 2016. RFIDJournal.com. URL: https://www.idexpert.ru/reviews/decathlon-uvelichivaet-prodazhi-i-snizhaet-poteri-blagodarya-rfid/?sphrase_id $=10284797$ (accessed: 02.27.2020).

27. X5 Retail Group will train staff in VR glasses. 2019. Retail.ru. URL: https://www.retail.ru/news/x5-retail-group-budet-obuchat-personal-v-vr-ochkakh/ (accessed: 02.20.2020).

\section{Ссылка для цитирования статьи For citation}

Ласкина Л.Ю., Силакова Л.В., Варакса А.М. 2020. Внедрение инноваций в ритейле и их влияние на стоимость компании. Экономика. Информатика. 47 (2): 274-287. DOI: 10.18413/2687-09322020-47-2-274-287.

Laskina L.Yu., Silakova L.V., Varaksa A.M. 2020. Innovations implementation in retail and its impact on a company value. Economics. Information technologies. 47 (2): 274-287 (in Russian). DOI: 10.18413/2687-0932-2020-47-2-274-287. 